\title{
Mechanical valves versus the Ross procedure for aortic valve replacement in children: Propensity-adjusted comparison of long-term outcomes
}

\author{
Bahaaldin Alsoufi, MD, ${ }^{\mathrm{a}}$ Zohair Al-Halees, MD, ${ }^{\mathrm{a}}$ Cedric Manlhiot, BSc, ${ }^{\mathrm{b}}$ Brian W. McCrindle, MD, MPH, ${ }^{\mathrm{b}}$

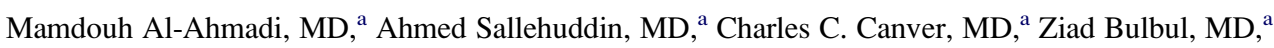 \\ Mansoor Joufan, MD, and Bahaa Fadel, MD ${ }^{\mathrm{a}}$
}

Objective: We aimed to identify characteristics differentiating children undergoing aortic valve replacement by using mechanical prostheses versus the Ross procedure and to compare survival and the need for aortic valve reoperation after each procedure.

\begin{abstract}
Methods: From 1983 to 2004, 346 children underwent aortic valve replacement (215 underwent the Ross procedure and 131 underwent placement of a mechanical prosthesis). Factors associated with procedure choice were used to construct a propensity score for use as a covariate in regression models to adjust for potential confounding by indication.
\end{abstract}

\begin{abstract}
Results: Patients undergoing the Ross procedure were younger, more likely to have a congenital cause, and less likely to have a rheumatic or connective tissue cause. They had a lower frequency of regurgitation, required more annular enlargement, and had less concomitant cardiac surgery. Competing-risk analysis showed that 16 years after aortic valve replacement, $20 \%$ of patients had died without subsequent aortic valve replacement, $25 \%$ underwent second aortic valve replacement, and 55\% remained alive without further replacement. After propensity adjustment, factors associated with early-phase death included mechanical valves and a nonrheumatic cause. Mechanical valves were also associated with constant-phase mortality. Repeated aortic valve replacement was associated with the Ross procedure and a rheumatic cause. Both factors were also associated with all-cause cardiac reoperation. In children receiving mechanical prostheses, younger age and smaller valve size were significant risk factors for death. Freedom from homograft replacement after the Ross procedure was $82 \%$ at 16 years of follow-up.
\end{abstract}

Conclusion: Results from this study showed good outcomes and an acceptable complication rate with both valve choices. Given the significantly increased risk of early and late death in younger children receiving smaller mechanical valves, the Ross procedure confers survival advantage in this age group at the expense of increased reoperation risk, especially in patients with a rheumatic cause.

Earn CME credits at

http://cme.ctsnetjournals.org

Supplemental material is available online.

\footnotetext{
From the King Faisal Heart Institute, ${ }^{\text {a }}$ King Faisal Specialist Hospital and Research Center, Riyadh, Saudi Arabia, and the Labatt Family Heart Center, ${ }^{\mathrm{b}}$ the Hospital for Sick Children and the University of Toronto, Toronto, Ontario, Canada.

Read at the Eighty-eighth Annual Meeting of The American Association for Thoracic Surgery, San Diego, Calif, May 10-14, 2008.

Received for publication May 6, 2008; revisions received Sept 9, 2008; accepted for publication Oct 9, 2008.

Address for reprints: Bahaaldin Alsoufi, MD, King Faisal Heart Institute (MBC 16), King Faisal Specialist Hospital and Research Center, PO Box 3354, Riyadh, Saudi Arabia 11211 (E-mail: balsoufi@hotmail.com).

J Thorac Cardiovasc Surg 2009; 137:362-70

$0022-5223 / \$ 36.00$

Copyright $@ 2009$ by The American Association for Thoracic Surgery

doi: 10.1016/j.jtcvs.2008.10.010
}

Aortic valve disease is common in children and frequently requires intervention. Congenital aortic valve disease is the most common pathology in North America and is encountered in approximately $5 \%$ of children with congenital heart disease. ${ }^{1-3}$ Although the incidence of rheumatic valve disease has significantly decreased in the Western world, it remains a major cause of aortic valvulopathy in developing countries. ${ }^{4}$ Several developments in interventional cardiology allow for early treatment of congenital aortic stenosis, and recent experience with aortic valve repair techniques showed encouraging short-term and midterm results in both congenital and rheumatic valve disease. ${ }^{5-8}$ Nonetheless, in patients with significant valve destruction or after repair or intervention failure, aortic valve replacement (AVR) is required. AVR in children is associated with several challenges. Although many replacement options are available, all alternatives have several limitations. ${ }^{2,3,9-13}$ AVR with a mechanical prosthesis and the Ross procedure using pulmonary autografts are the most commonly used valve substitutes in children. Mechanical valves in children are associated with increased frequency of complications, including morbidity related to long-term anticoagulation, 


\section{Abbreviations and Acronyms \\ $\mathrm{AVR}=$ aortic valve replacement \\ LVOT $=$ left ventricular outflow tract \\ $\mathrm{PE}=$ parameter estimate \\ RVOT $=$ right ventricular outflow tract}

deterioration of ventricular function caused by the development of patient-prosthesis mismatch as the child outgrows the initial valve, and the need for subsequent prosthetic valve replacement. $^{2,3,11-13}$ On the other hand, although the Ross procedure has growth potential and does not require longterm anticoagulation, the procedure is technically demanding, and late autograft failure, aortic root dilatation, and homograft reoperations are common. ${ }^{2-4,14-25}$

Although several case series exist in the literature reporting outcomes after AVR in children, only a few offered comparisons between different valve options. We aimed to review a large single-institution experience with AVR in children and to compare indications and outcomes of children undergoing mechanical valve replacement with those of children undergoing the Ross procedure while adjusting for potential confounding by indication.

\section{MATERIALS AND METHODS Inclusion Criteria}

From 1983 to 2005, 346 consecutive children under the age of 18 years required AVR at the King Faisal Specialist Hospital and Research Center in Riyadh, Saudi Arabia. Those patients received either a bileaflet mechanical prosthesis $(n=131)$ or underwent the Ross procedure $(n=215)$. In the current study we did not include children who had undergone AVR with ball or tilting-disc valves because those prostheses are not commonly used anymore, and therefore their inclusion would not be relevant to current clinical practice. Patients were identified by using the hospital surgical database. Clinical, operative, and outcome data were abstracted from medical records. Approval of this study was obtained from the research ethics board at our institution, and requirement for individual consent was waived for this observational study.

\section{Operative Details}

Detailed steps of the surgical intervention will not be discussed in this section; however, some important information will be briefly listed. ${ }^{4}$ Midline sternotomy was performed, and standard cardiopulmonary bypass and myocardial protection techniques were used in all cases. For AVR with a mechanical prosthesis, the valve was secured to the annulus with multiple mattressed sutures, with the pledgets placed at the ventricular aspect of the annulus. For the Ross procedure, the pulmonary autograft was implanted as a full root, with coronary transfer in all cases. The autograft muscle cuff was trimmed with sutures placed almost directly at the autograft annulus. The proximal suture line was performed with running polypropylene sutures. The neoaortic annulus was not reinforced in these patients, so as not to limit growth. In patients with left ventricular outflow tract (LVOT) obstruction, a modified Ross-Konno technique was used. Part of the septum was cored out to completely open up the LVOT without creating a large ventricular septal defect. In those patients the fibrous annulus of the aortic valve was often divided, and the cut was partially taken down to the septum. In our current practice, in patients with a dilated aortic annulus of greater than 29 to
$30 \mathrm{~mm}$ or with an aortic annulus 2 to $3 \mathrm{~mm}$ larger than the pulmonary valve annulus, the Ross procedure is not considered, and we rarely use any aortic annulus reduction techniques. The distal suture line was occasionally reinforced with Teflon felt in patients with a dilated ascending aorta.

The immediate postoperative results were assessed in all patients in the operating room by means of transesophageal echocardiographic analysis.

\section{Follow-up}

Patients were evaluated clinically and by means of detailed echocardiographic analysis on discharge, 6 weeks after the operation, at 6 months, and yearly thereafter. Patients with mechanical valves were started on intravenous heparin, maintaining the partial thromboplastin time ratio at between 1.5 and 2 times that of baseline. In addition, all patients received oral sodium warfarin, aiming to maintain an international normalized ratio within the range of 2.0 to 3.0. Subsequent to hospital discharge, anticoagulation was followed by specialized local anticoagulation clinics with established monitoring protocols.

Late outcomes were determined from recent office visits at King Faisal Specialist Hospital and Research Center or from direct correspondence with patients' families. The median follow-up duration was 6.3 years and was longer for patients who received a mechanical prosthesis $(8.3$ years; range, up to 22.9 years) versus those who underwent the Ross procedure (5.7 years; range, up to 16.4 years; $P=.01$ ).

\section{Statistical Analysis}

Data are presented as means with standard deviations, medians with minimums and maximums, and frequencies, as appropriate. Differences in patients' characteristics were calculated by using Student's $t$ tests with the Sattertwaite correction and the Fisher's exact test. Time-dependent outcomes after AVR were parametrically modeled by using up to 3 phases of risk (early, constant, and late) as necessary. Competing-risk analysis was performed to model the probability over time of each of 3 mutually exclusive end points: death, valve reoperation, and alive and free from reoperation. Non-time-dependent outcomes were modeled in logistic regression models.

To correct for confounding by indication in the procedure assignment (mechanical valve placement or the Ross procedure), a propensity score was created, modeling the probability of every patient to be assigned to the mechanical valve procedure over the Ross procedure based on patient demographics and medical characteristics. Variable selection was based on univariate differences between groups (a priori), with backward selection in the logistic multivariable equation to obtain the final model. A total of 8 variables were selected ( 7 of them statistically significant in the model) for an events-per-variable value of 16.4 (see Table E1). The model was highly statistically significant $(P<.0001)$ and had excellent discriminatory power (c-statistic $=0.883$ ). There was no colinearity between variables, and no interaction criteria were included. There was very limited overlap between propensity scores in both groups, and therefore we used it as a covariate in statistical models. Differences in outcomes between the patients who had a mechanical valve procedure or the Ross procedure are reported in the form of hazard/odds ratios for event if the patient has a mechanical valve procedure instead of the Ross procedure in both propensity-unadjusted models and propensity-adjusted models.

Variables other than aortic valve type, potentially affecting the likelihood of mortality and reoperation, including sex, year of operation, age at operation, cause, pathology, previous operations, preoperative catheter intervention, concomitant cardiac operation, and LVOT enlargement, were included in a multivariable stepwise model $(P<.05$ to enter) along with aortic valve type. Backward selection was used to obtain final models for all individual phases of risk for both outcomes. Finally, procedure-specific variables (mechanical valve size, homograft size, homograft preservation [fresh or cryopreserved], and homograft type [pulmonary or aortic]) were modeled individually in each phase of risk for both mortality and reoperation. The 
TABLE 1. Patients' characteristics

\begin{tabular}{|c|c|c|c|c|}
\hline & Cohort $(n=346)$ & Mechanical prosthesis $(n=131[38 \%])$ & Ross procedure $(n=215[62 \%])$ & $P$ value \\
\hline Sex (male) & $260(75 \%)$ & $109(83 \%)$ & $151(70 \%)$ & .007 \\
\hline Mean age at surgical intervention (y) & $12.4 \pm 4.4$ & $14.0 \pm 3.8$ & $11.4 \pm 4.6$ & $<.0001$ \\
\hline Median year at presentation & $1998(1983-2005)$ & $1996(1983-2005)$ & 1999 (1991-2004) & $<.0001$ \\
\hline \multicolumn{5}{|l|}{ Cause } \\
\hline Rheumatic & $201(58 \%)$ & $97(74 \%)$ & $104(48 \%)$ & $<.0001$ \\
\hline Congenital & $116(34 \%)$ & $15(11 \%)$ & $101(47 \%)$ & $<.0001$ \\
\hline Connective tissue & $14(4 \%)$ & $12(9 \%)$ & $2(1 \%)$ & $<.0001$ \\
\hline Endocarditis & $15(4 \%)$ & $7(5 \%)$ & $8(4 \%)$ & .59 \\
\hline \multicolumn{5}{|l|}{ Hemodynamic manifestation } \\
\hline Stenosis & $44(13 \%)$ & $8(6 \%)$ & $36(17 \%)$ & .005 \\
\hline Regurgitation & $224(65 \%)$ & $115(88 \%)$ & $109(49 \%)$ & $<.0001$ \\
\hline Mixed & $78(22 \%)$ & $8(6 \%)$ & $70(33 \%)$ & $<.0001$ \\
\hline Previous percutaneous intervention & $20(6 \%)$ & $0(0 \%)$ & $20(9 \%)$ & $<.0001$ \\
\hline Previous cardiac operation & $97(28 \%)$ & $41(31 \%)$ & $56(26 \%)$ & .33 \\
\hline One previous operation & $89(26 \%)$ & $36(27 \%)$ & $53(25 \%)$ & \\
\hline Two previous operations & $8(2 \%)$ & $5(4 \%)$ & $3(1 \%)$ & \\
\hline Concomitant cardiac operation & $147(42 \%)$ & $97(74 \%)$ & $50(23 \%)$ & $<.0001$ \\
\hline Arch repair & $5(1 \%)$ & $4(3 \%)$ & $1(<1 \%)$ & .07 \\
\hline Left ventricular outflow tract enlargement & $35(16 \%)$ & $3(2 \%)$ & $32(15 \%)$ & $<0.0001$ \\
\hline
\end{tabular}

clinical relevance of covariates found to influence outcomes was established through stratification analysis.

All statistical analyses were performed with SAS statistical software version 9.1 (SAS Institute, Inc, Cary, NC).

\section{RESULTS}

\section{Patient Characteristics}

There were $260(75 \%)$ male patients. The mean age at the time of the index operation was $12.4 \pm 4.4$ years. The underlying valve pathology was rheumatic in $201(58 \%)$ patients, congenital in $116(34 \%)$ patients, endocarditis in $15(4 \%)$ patients, and connective tissue disease in $14(4 \%)$ patients. The hemodynamic aortic valve dysfunction was primarily regurgitation in $224(65 \%)$ patients, stenosis in $44(13 \%)$ patients, and mixed in $78(22 \%)$ patients.

Before AVR, 20 (6\%) patients had undergone percutaneous aortic valve interventions, and $97(28 \%)$ patients had undergone surgical intervention to address aortic valve lesions, other cardiac lesions, or both. Patients' demographic and operative characteristics at the time of AVR are listed in Table 1.

In our series concomitant cardiac surgery was required in $147(42 \%)$ patients, and LVOT enlargement was required in $35(16 \%)$ children, whereas arch repair was performed in 5 $(1 \%)$ children (Table 1$)$.

The most commonly used mechanical prosthesis was Carbomedics (Austin, Tex; $\mathrm{n}=123$ ), followed by St Jude ( $\mathrm{St}$ Paul, Minn; $\mathrm{n}=8$ ). Mean mechanical valve size was 22.1 $\pm 2.5 \mathrm{~mm}$. The mean pulmonary homograft size used for reconstruction of the right ventricular outflow tract (RVOT) in the Ross procedure was $22.7 \pm 2.4 \mathrm{~mm}$. Fresh homografts were used in $52 \%$ of patients undergoing the Ross procedure, whereas cryopreserved homografts were used in
$48 \%$. Pulmonary homografts were used in $83 \%$ of patients undergoing the Ross procedure, whereas $17 \%$ received aortic homografts. Homografts were not generally matched for the blood group of the patients.

\section{Factors Associated with the Choice of Ross Procedure Versus Mechanical AVR}

The Ross procedure was introduced at our institution in 1990, and since then, it has become the most common procedure performed for AVR in children. AVR with a mechanical prosthesis has been used at our institution since the beginning of this study period in 1983. Female patients were found to be more likely to undergo a Ross procedure than to receive a mechanical prosthesis. Children who underwent the Ross procedure were younger, presented in more recent years, and were more likely to have a congenital cause, preoperative stenosis, or mixed aortic disease. Patients who had a mechanical valve placed were older, presented in earlier years, and were more likely to have a rheumatic or connective tissue cause and preoperative aortic regurgitation and to have undergone concomitant cardiac surgery. Arch repair was somewhat more likely in the mechanical valve group, whereas concomitant LVOT enlargement was more likely in the Ross procedure group. In patients undergoing the Ross procedure, concomitant surgical intervention was mainly mitral valve repair $(n=39)$ in addition to a few cases of ventricular septal defect closure, coronary artery bypass grafting, and pulmonary angioplasty. On the other hand, concomitant surgical intervention in patients receiving a mechanical aortic prosthesis included mitral valve replacement $(n=71)$, mitral valve repair $(n=7)$, tricuspid 
TABLE 2. Incremental risk factors for time-related transition from initial AVR to either death or a second AVR

\begin{tabular}{|c|c|c|c|c|}
\hline & \multicolumn{2}{|c|}{ Unadjusted } & \multicolumn{2}{|c|}{ Propensity adjusted } \\
\hline & Estimate \pm SE & $P$ value & Estimate \pm SE & $P$ value \\
\hline \multicolumn{5}{|c|}{ Death without subsequent AVR: Early phase } \\
\hline Valve type (mechanical vs Ross) & $2.05 \pm 0.57$ & .0004 & $2.71 \pm 0.70$ & .0001 \\
\hline Cause other than rheumatic & $1.75 \pm 0.77$ & .03 & $2.10 \pm 0.69$ & .003 \\
\hline Younger age at surgical intervention & $0.12 \pm 0.05$ & .03 & & \\
\hline \multicolumn{5}{|c|}{ Death without subsequent AVR: Constant phase } \\
\hline Valve type (mechanical vs Ross) & $1.60 \pm 0.58$ & .007 & $1.72 \pm 0.65$ & .009 \\
\hline Concomitant operations & $2.74 \pm 1.01$ & .007 & & \\
\hline \multicolumn{5}{|l|}{ Survival to a subsequent AVR: Late phase } \\
\hline Valve type (Ross vs mechanical) & $2.72 \pm 0.48$ & $<.0001$ & $2.47 \pm 0.47$ & $<.0001$ \\
\hline Rheumatic cause & $1.92 \pm 0.62$ & .002 & $2.09 \pm 0.61$ & .0006 \\
\hline Concomitant cardiac surgery & $0.91 \pm 0.38$ & .02 & & \\
\hline
\end{tabular}

$A V R$, Aortic valve replacement; $S E$, standard error.

valve repair $(\mathrm{n}=16)$, tricuspid valve replacement $(\mathrm{n}=$ $1)$, aortic root replacement $(\mathrm{n}=8)$, and right ventriclepulmonary artery conduit change $(n=5)$. The frequency of previous cardiac operation was similar between groups (Table 1).

\section{Competing Risk Analysis for Death or Subsequent Prosthesis Replacement After Initial AVR}

After the 346 initial AVRs, 36 patients had their valves subsequently replaced, and 32 patients died without a further AVR, including $13(3.7 \%)$ operative deaths. The hazard function for time-related transition to a second AVR was characterized by the presence of a late hazard phase that steadily increases as years since surgical intervention progressed (see Figure E1). The hazard function for time-related transition to death without a second AVR was characterized by an early hazard phase with a high level of risk in the immediate postoperative period and a constant hazard phase indicating a continuous attrition rate over time (see Figure E2). The competing risks for the 2 events showed that at 16 years after AVR, approximately $20 \%$ of patients have died, $25 \%$ have undergone a second aortic valve reoperation, and $55 \%$ are alive and free from aortic reoperation (see Figure E3).

\section{Factors Associated with Mortality}

There were $13(3.7 \%)$ operative deaths: $5(2.3 \%)$ in patients undergoing the Ross procedure and $8(6.1 \%)$ in patients receiving a mechanical prosthesis. Furthermore, there were 19 additional deaths during the follow-up duration; all were of patients who received a mechanical prosthesis. Factors associated with higher risk of death after initial AVR were sought, and results are shown in Table 2.

Unadjusted risk analysis showed that variables linked to early-phase mortality included the placement of a mechanical valve, younger age at the time of valve replacement, and an underlying cause other than rheumatic. In addition to mechanical valves, concomitant cardiac surgery was related to higher constant-phase mortality risk.
An effect of younger age on increased early-phase mortality was seen in children undergoing AVR with a mechanical prosthesis but neutralized in those undergoing the Ross procedure, as seen in the predictive model shown in Figure 1. Moreover, smaller mechanical valve prosthesis size, strongly linked to age at initial AVR, was associated with constant-phase mortality (hazard ratio, $1.5 / \mathrm{mm} ; 95 \%$ confidence interval, 1.2-1.9; $P=.0007$; see Figure E4).

In propensity-adjusted analysis placement of a mechanical valve was associated with both early-phase (parameter estimate $[\mathrm{PE}], 2.7 \pm 0.7 ; P=.0001)$ and constant-phase (PE, $1.7 \pm 0.7 ; P=.009$ ) mortality risk (Figure 2 ). Underlying cause other than rheumatic remained a significant risk factor for early-phase mortality after propensity adjustment (PE, $2.1 \pm 0.7 ; P=.003)$.

\section{Factors Associated with Aortic Valve Reoperation}

During follow-up, there were 36 aortic valve reoperations: 8 in patients who have received a mechanical prosthesis and 28 in patients who had a Ross procedure. Factors associated with the time-related risk of subsequent replacement after initial AVR were sought, and results are shown in Table 2.

Unadjusted risk analysis showed that variables linked to aortic valve reoperation included undergoing the Ross procedure, underlying rheumatic cause, and concomitant cardiac surgery. In addition, placement of a small prosthesis was associated with increased risk for aortic valve reoperation in children who received a mechanical prosthesis (hazard ratio, 1.5/mm; 95\% confidence interval, $1.2-3.9 ; P=.05)$.

In propensity-adjusted analysis the Ross procedure was strongly linked with late-phase reoperation risk (PE, $2.5 \pm$ $0.5 ; P<.0001$ ), as shown in Figure 3. Additionally, underlying rheumatic pathology was an important risk factor for late subsequent aortic valve reoperation $(\mathrm{PE}, 2.1 \pm 0.6$; $P=.0006$; see Figure E5). This effect was more apparent in patients who underwent a Ross operation compared with those who received a mechanical prosthesis (Figure 4). We analyzed whether the hemodynamic manifestation 


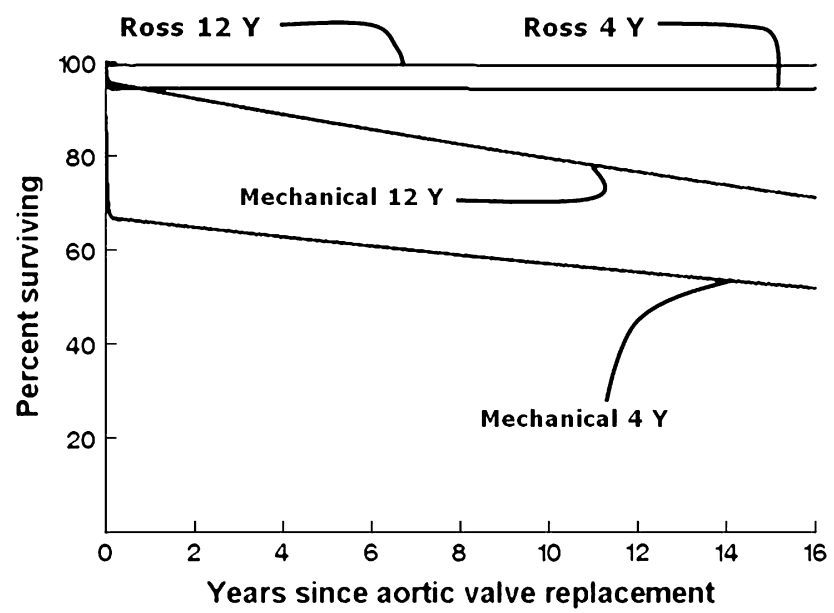

FIGURE 1. Survival without repeated aortic valve reoperation stratified by age in patients undergoing aortic valve replacement with the Ross procedure versus placement of a mechanical prosthesis. The effect of younger age on early-phase mortality was neutralized for patients undergoing the Ross procedure because the 2 lines almost overlap, whereas the effect remained significant for those undergoing aortic valve replacement with a mechanical prosthesis. Solid lines represent parametric point estimates.

before initial AVR was a contributing factor to valve reoperation, especially in patients with a rheumatic cause undergoing the Ross procedure. The presence of pure regurgitation, stenosis, or mixed disease did not significantly influence subsequent reoperation (see Figure E6).

\section{Factors Associated with Any Cardiac Reoperation}

A total of 68 patients (49 undergoing the Ross procedure and 19 receiving a mechanical prosthesis) had a cardiac reoperation, including but not limited to a second AVR. At 16 years after AVR, about $40 \%$ of patients have undergone

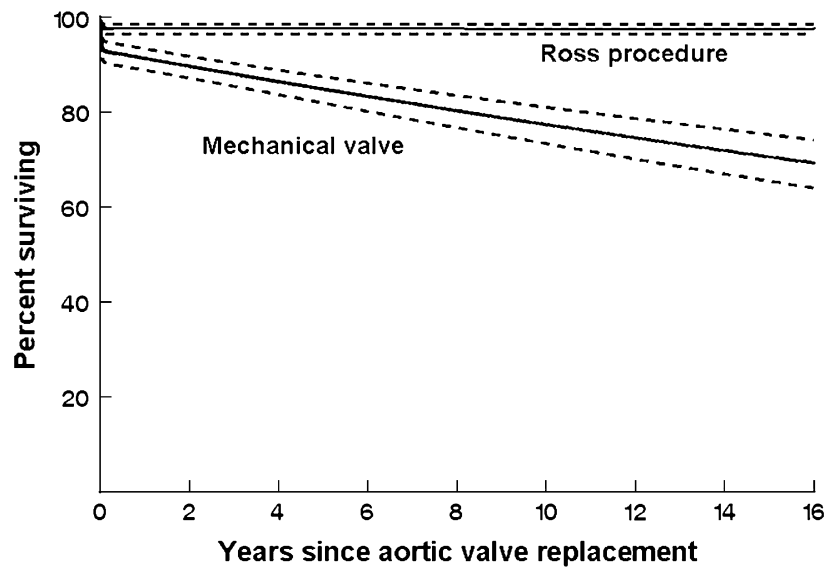

FIGURE 2. Propensity-adjusted effect of initial aortic valve replacement type (Ross procedure or mechanical prosthesis) on survival without repeated aortic valve reoperation. The solid lines represent parametric point estimates, and the dashed lines enclose the $95 \%$ confidence interval.

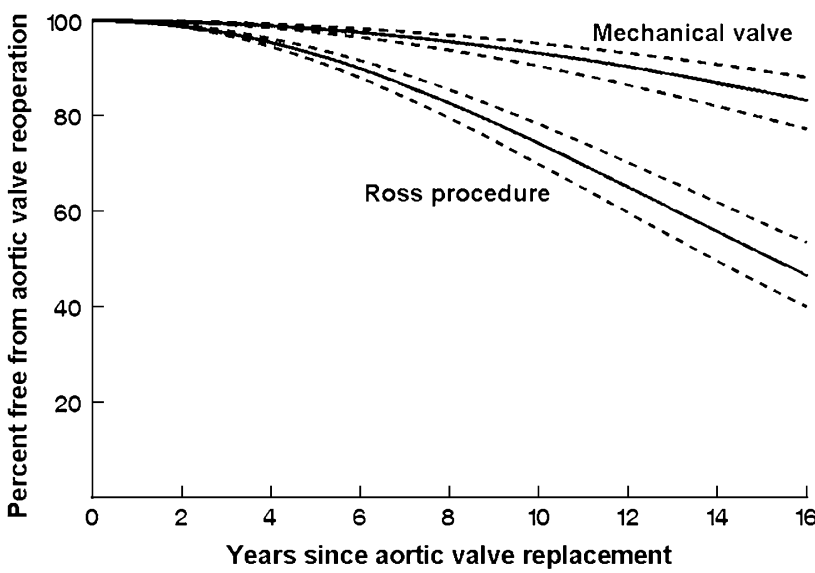

FIGURE 3. Propensity-adjusted effect of initial aortic valve replacement type (Ross procedure or mechanical prosthesis) on survival to repeated aortic valve reoperation. The solid lines represent parametric point estimates, and the dashed lines enclose the $95 \%$ confidence interval.

additional cardiac operations. In competing-risk models factors associated with any cardiac reoperation were the same as those associated with increased risk of survival to subsequent AVR (see Figure E7), with the exception of LVOT enlargement $(\mathrm{PE}, 1.55 \pm 0.43 ; P=.0004)$ at the initial intervention, which was found to increase time-related risk of surviving to cardiac reoperation.

\section{Functional Status and Additional Late Morbidity}

At the most recent follow-up, the majority of survivors $(91 \%)$ had normal clinical exercise ability and were in New York Heart Association functional class I. There was no significant difference in the number of patients in New York Heart Association class greater than 1 between those

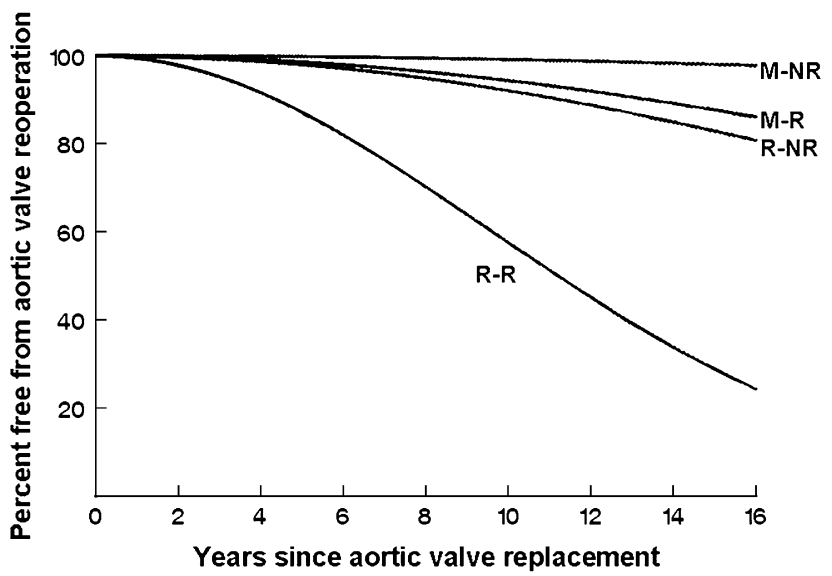

FIGURE 4. Propensity-adjusted effect of initial aortic valve replacement type (Ross procedure or mechanical prosthesis) and disease cause on survival to repeated aortic valve reoperation. The solid lines represent parametric point estimates. $M-N R$, Mechanical nonrheumatic; $M-R$, mechanical rheumatic; $R-N R$, Ross nonrheumatic; $R-R$, Ross rheumatic. 
undergoing the Ross procedure (8\%) and mechanical valve recipients $(13 \%)$.

For patients who underwent the Ross procedure, 16-year freedom from homograft reoperation was 82\% (Figure E8). Homograft reoperation was not influenced by the type of conduit.

Although there was an apparent increase in valve-related morbidity in children who received mechanical prostheses, that difference did not reach statistical significance because of the limited numbers of documented valve-related morbid events. All anticoagulation-related and thromboembolic complications were obviously in patients who received a mechanical prosthesis: bleeding $(\mathrm{n}=3)$, valve thrombosis $(n=2)$, and embolization $(n=2)$. There were 3 episodes of endocarditis, all requiring reoperation and aortic valve rereplacement: 2 were after the Ross procedure and 1 was after mechanical valve replacement.

\section{DISCUSSION}

Our study reports a single institution's experience with AVR by using bileaflet mechanical valves or the Ross procedure in 346 children. Competing-risks analysis was chosen because these patients were simultaneously at risk for 2 mutually exclusive events: death and reoperation with prosthesis replacement. Conventional time-related analyses consider individual events, such as death or reoperation, either in isolation or as a combined end point. Although useful, they do not address the question of how often an event might occur in the absence of other events for which a patient is at simultaneous risk.

\section{Factors Associated with the Choice of Ross Procedure Versus Mechanical Valve}

The primary objective of this study was to determine the effect of AVR choice on survival and reoperation in children with aortic valve disease. However, examination of the data revealed important differences between these 2 patient groups. Patients undergoing replacement with a mechanical valve were more likely to have associated cardiac diseases requiring concomitant cardiac surgery and more likely to have a rheumatic or connective tissue cause. Children undergoing the Ross procedure, on the other hand, were younger, more likely to have congenital valve disease, or more likely to require enlargement of the LVOT. Many of those variables can influence mortality and reoperation risk. The disparity of characteristics of patients undergoing the Ross procedure versus mechanical valve placement decreases the usefulness of unadjusted comparison. Propensity-adjusted analysis allows fair comparison to determine the effect of procedure type on short- and long-term outcomes.

\section{Mortality Risk}

Several variables were found to significantly increase the risk of mortality. Mechanical valves were associated with early- and constant- phase mortality. This is in line with other reports indicating an operative survival advantage for the Ross procedure over mechanical valve placement. ${ }^{2,3}$ Despite surgical complexity, the Ross procedure is safe in experienced hands. In our series mortality was $2.3 \%$, which is similar to the data from the International Registry for the Ross Procedure (2.5\%) compared with $6.1 \%$ for mechanical valves.

Despite high association with concomitant cardiac and multivalvular surgery, early mortality after AVR for a rheumatic cause was less than $1 \%$ compared with $7 \%$ for other causes.

Younger age was found to be significant in unadjusted analysis. The effect of age was neutralized in patients undergoing the Ross procedure but remained important in the mechanical prosthesis group. Operative mortality for patients younger than 5 years in our study was $50 \%$ for mechanical valves, whereas it was less than $4 \%$ for the Ross procedure. Additionally, the need for LVOT enlargement (Ross-Konno procedure) was not associated with a significant increase in operative mortality $(6 \%)$. In children less than 2 years of age, our experience with the Ross procedure remains limited to 10 patients with 1 operative death.

More importantly, survival was stable for the Ross procedure, with no late mortality compared with 19 additional cardiac-related deaths in the mechanical prosthesis group. Many of those deaths were sudden in nature, highlighting the delicate problem of compliance with the anticoagulation regimen and its implication on patients' lifestyle that is especially difficult to control in children and young adults. Despite having well-established anticoagulation protocols and follow-up within specialized anticoagulation clinics in Saudi Arabia, educational and social factors might influence compliance with the anticoagulation protocol, and therefore these late outcomes might differ in the Western world compared with those seen in other countries. On the other hand, several other publications from North America and Europe similarly reveal a steady attrition rate in children who have received mechanical prostheses, indicating that this anticoagulation problem in children remains true in developed countries. $^{2,3,11-13}$

\section{Reoperation Risk}

The Ross procedure was a risk factor for aortic valve reoperation and overall cardiac reoperations. There were 28 children thus far who have required AVR at a median of 2.8 years after the Ross procedure. Twenty-seven of those patients who had a rheumatic cause, and 26 had pure aortic regurgitation preoperatively. We have previously reported higher autograft reoperation rates in rheumatic patients compared with those with other causes. ${ }^{4,5}$ The mode of failure in our series included aortic root dilatation and cusp elongation and prolapse in $46 \%$, recurrent rheumatic disease in $25 \%$, an inflammatory process that is likely recurrent rheumatic 
disease in $18 \%$, aneurysm formation in $7 \%$, and endocarditis in $4 \%$. We have previously identified risk factors for autograft failure, and those include active rheumatic heart disease, concomitant severe rheumatic mitral regurgitation, pure regurgitation with severe dilatation of the LVOT greater than $29 \mathrm{~mm}$, or discrepancy between the LVOT and RVOT of greater than 2 to $3 \mathrm{~mm}$ in favor of the LVOT. ${ }^{5}$ By adhering to new selection criteria and avoiding patients with the above listed risk factors and by adapting surgical modifications, such as careful trimming of the muscle rim under the autograft and suturing close to the annulus because this muscle rim might dilate and contribute to future failure and occasional reinforcement of the dilated sinotubular junction, we expect that we will be encountering less instances of autograft failures in patients with a rheumatic cause. Since adopting those changes in 1999, only 2 patients with a rheumatic cause required autograft change. Despite a relatively shorter follow-up period, this finding is encouraging considering that most failures were previously evident in the first 2 to 3 years after surgical intervention.

Concerns of pulmonary autograft dilatation have stimulated recent developments in surgical strategies to address late root dilatation. Most recently, inspired by a technique that was previously used in mitral valve replacement with a pulmonary autograft, Slater and colleagues ${ }^{26}$ described a modified pulmonary autograft implantation procedure in which the pulmonary autograft was encased in a Dacron tube to prevent future dilatation. They suggested that this procedure can be applied to fully grown children and young adults and reported excellent short-term results with respect to autograft valve function and lack of dilatation of the annulus or sinotubular junction. ${ }^{26}$

\section{Implications on Clinical Practice Internationally}

Our patient population is different from that in published reports from the Western world because of the high percentage of rheumatic valve disease. Nonetheless, important information can be obtained from our analysis to help in the difficult decision of AVR strategy in children.

In the Western world the prevalence of rheumatic valve disease is much less, and the majority of patients undergoing AVR have underlying congenital pathology. Children with congenital aortic valve disease might require surgical intervention at an early age and have small annuluses requiring LVOT enlargement. Based on our analysis, the Ross procedure confers survival advantage in this population because mortality risk is low in experienced centers, and some risk factors for mortality are neutralized in this population compared with mechanical valves, in which younger age and smaller prostheses remain important risk factors for early and late death. Similarly, freedom from autograft reoperation in patients without a rheumatic cause after the Ross procedure was high, and therefore the projected autograft longevity in Western series is longer. Into the bargain, mortality risk during valve reoper- ation in the current era is low, and valve-preserving root replacement techniques in cases associated with root dilatation and autograft regurgitation have been described, which might increase valve longevity despite aortic wall reintervention. ${ }^{27}$

RVOT reoperation remains a concern in patients after the Ross procedure. Again, mortality risk during RVOT reintervention is low, and recent advances with percutaneous pulmonary valve replacement might allow cardiologists to address this problem without surgical intervention. ${ }^{28}$ The immediate and short-term results of percutaneous pulmonary valve implantation are very encouraging, and these procedures were recently performed at our institution in patients after the Ross procedure with excellent immediate results. ${ }^{27}$ The perceived additional advantages of the Ross procedure in children, such as improved survival, the avoidance of anticoagulation-related morbidity, the ability to match somatic growth, and the concern of anticoagulation during pregnancy in female patients, might encourage surgeons to consider the Ross procedure in children as the aortic valve substitute of choice despite RVOT reintervention incidence.

\section{Study Limitations}

The present report is a retrospective analysis of patients from a single institution with diverse anatomy who underwent an operation during a 22-year time span. Despite the use of a comprehensive set of variables in all analyses, unmeasured covariates might have contributed to disparate outcomes in the recipient populations. In addition, this study addresses survival and reoperation after AVR in children but does not examine the effect of prosthesis type on cardiac hemodynamics, left ventricular recovery, and ventricular and aortic root dimensions.

\section{CONCLUSIONS}

The study suggests excellent functional status and acceptable complication rates with both valve choices. Given a significantly increased risk of early and late death in younger children receiving smaller mechanical valves, the Ross procedure confers survival advantages in this age group at the expense of increased reoperation risk, especially in patients with a rheumatic cause.

\section{References}

1. Salomon NW, Stinson EB, Oyer P, Copeland JG, Shumway NE. Operative treatment of congenital aortic stenosis. Ann Thorac Surg. 1978;26:452-60.

2. Brown JW, Ruzmetov M, Vijay P, Rodefeld MD, Turrentine MW. Surgery for aortic stenosis in children: a 40-year experience. Ann Thorac Surg. 2003;76: 1398-411.

3. Karamlou T, Jang K, Williams WG, Caldarone CA, Van Arsdell G, Coles JG, et al. Outcomes and associated risk factors for aortic valve replacement in 160 children: a competing-risks analysis. Circulation. 2005;112:3462-9.

4. Al Halees Z, Pieters F, Qadoura F, Shahid M, Al-Amri M, Al-Fadley F. The Ross procedure is the procedure of choice for congenital aortic valve disease. J Thorac Cardiovasc Surg. 2002;123:437-41.

5. Tweddell JS, Pelech AN, Frommelt PC, Jaquiss RD, Hoffman GM, Mussatto KA, et al. Complex aortic valve repair as a durable and effective alternative to valve 
replacement in children with aortic valve disease. $J$ Thorac Cardiovasc Surg. 2005; 129:551-8.

6. Alsoufi B, Karamlou T, Bradley T, Williams WG, Van Arsdell GS, Coles JG, et al. Short and midterm results of aortic valve cusp extension in the treatment of children with congenital aortic valve disease. Ann Thorac Surg. 2006;82: 1292-9.

7. Al Halees Z, Al Shahid M, Al Sanei A, Sallehuddin A, Duran C. Up to 16 years follow-up of aortic valve reconstruction with pericardium: a stentless readily available cheap valve? Eur J Cardiothorac Surg. 2005;28:200-5.

8. Kalangos A, Beghetti M, Baldovinos A, Vala D, Bichel T, Mermillod B, et al. Aortic valve repair by cusp extension with the use of fresh autologous pericardium in children with rheumatic aortic insufficiency. J Thorac Cardiovasc Surg. 1999; 118:225-36.

9. Alexiou C, McDonald A, Langley SM, Dalrymple-Hay MJR, Haw MP, Monro JL. Aortic valve replacement in children: are mechanical prostheses a good option? Eur J Cardiothorac Surg. 2000;17:125-33.

10. Mazzitelli D, Guenther T, Schreiber C, Wottke M, Michel J, Meisner H. Aortic valve replacement in children: are we on the right track? Eur $J$ Cardiothorac Surg. 1998; 13:565-71.

11. Turrentine MW, Ruzmetov M, Vijay P, Bills RG, Brown JW. Biological versus mechanical aortic valve replacement in children. Ann Thorac Surg. 2001; 71(suppl):S356-60

12. Starnes VA, Luciani GB, Wells WJ, Allen RB, Lewis AB. Aortic root replacement with the pulmonary autograft in children with complex left heart obstruction. Ann Thorac Surg. 1996;62:442-8.

13. Elkins RC, Lane MM, McCue C. Ross operation in children: late results. J Heart Valve Dis. 2001;10:736-41.

14. Hraska V, Krajci M, Ch Haun, Ntalakoura K, Razek V, Lacour-Gayet F, et al. Ross and Ross-Konno procedure in children and adolescents: mid-term results. Eur J Cardiothorac Surg. 2004;25:742-7.

15. Marino BS, Wernovsky G, Rychik J, Bockoven JR, Godinez RI, Spray TI. Early results of the Ross procedure in simple and complex left heart disease. Circulation. 1999;100(suppl 2):S162-6.

16. Khwaja S, Nigro JJ, Starnes VA. The Ross procedure is an ideal aortic valve replacement operation for the teen patient. Semin Thorac Cardiovasc Surg Pediatr Card Surg Annu. 2005;173-5.

17. Kadner A, Raisky O, Degandt A, Tamisier D, Bonnet D, Sidi D, et al. The Ross procedure in infants and young children. Ann Thorac Surg. 2008;85:803-9.

18. Ohye RG, Gomez CA, Ohye BJ, Goldberg CS, Bove AL. The Ross/Konno procedure in neonates and infants: intermediate-term survival and autograft function. Ann Thorac Surg. 2001;72:823-30.

19. Laudito A, Brook MM, Suleman S, Bleiweis MS, Thompson LD, Hanley FL, et al. The Ross procedure in children and young adults: a word of caution. J Thorac Cardiovasc Surg. 2001;122:147-53.

20. David TE, Omran A, Ivanov J, Armstrong S, de Sa MP, Sonnenberg B, et al. Dilation of the pulmonary autograft after the Ross procedure.J Thorac Cardiovasc Surg. 2000;119:210-20.

21. Solymar L, Sudow G, Holmgren D. Increase in size of the pulmonary autograft after the Ross operation in children: growth or dilation? J Thorac Cardiovasc Surg. 2000;119:4-9.

22. Jonas RA. The Ross procedure is not the procedure of choice for the teenager requiring aortic valve replacement. Semin Thorac Cardiovasc Surg Pediatr Card Surg Annu. 2005;176-80.

23. Pasquali SK, Cohen MS, Shera D, Wernovsky G, Spray TL, Marino BS. The relationship between neo-aortic root dilation, insufficiency, and reintervention following the Ross procedure in infants, children and young adults. J Am Coll Cardiol. 2007;49:1806-12.

24. Al-Halees Z, Kumar N, Gallo R, Gometza B, Duran C. Pulmonary autograft for aortic valve replacement in rheumatic disease: a caveat. Ann Thorac Surg. 1995;60(suppl):S172-6.

25. Pieters F, Al-Halees Z, Zwaan F, Hatle L. Autograft failure after the Ross operation in a rheumatic population: pre and postoperative echocardiographic observations. J Heart Valve Dis. 1996;5:404-9.

26. Slater MS, Shen I, Welke K, Komanapalli C, Ungerleider R. Modification to the Ross procedure to prevent autograft dilatation. Semin Thorac Cardiovasc Surg Pediatr Card Surg Annu. 2005;181-4.

27. Ishizaka T, Devaney EJ, Ramsburgh SR, Suzuki T, Ohye RG, Bove EL. Valve sparing aortic root replacement for dilatation of the pulmonary autograft and aortic regurgitation after the Ross procedure. Ann Thorac Surg. 2003;75:1518-22.

28. Nordmeyer J, Coats L, Bonhoeffer P. Current experience with percutaneous pulmonary valve implantation. Semin Thorac Cardiovasc Surg. 2006;18:122-5.

\section{Discussion}

Dr Vaughn A. Starnes (Los Angeles, Calif). Dr Alsoufi and colleagues have performed a retrospective analysis on 346 children receiving aortic valves, either mechanical prostheses or the Ross procedure, over a 21-year period. The operative experience was from 1983 to 2004. In an attempt to neutralize confounding in the selection of a prosthesis, a propensity-adjustment comparison was performed. In summary, we have heard that the Ross procedure confers survival advantage over the mechanical cohort because of the higher operative mortality and the continuous attrition in the late follow-up period in the mechanical group.

I agree with the conclusions of the article, and I also support the use of the Ross procedure over the mechanical valve in children. The reason mechanical valves fail in children include lack of growth of the prosthesis, leading to a patient-prosthesis mismatch; valve failure caused by pannus formation; poor compliance with taking medications (warfarin), particularly in adolescents; and, in women, the issue of pregnancy and warfarin. I have 3 questions.

Your analysis using a propensity-adjusted comparison was performed to neutralize, as best you could, confounding variables that overlap, but we have 1 curious nonoverlapping variable that I would like to ask you about: the time of the study. From 1983 to 1990 , you used mechanical valves alone, according to your article. Would it not have been better to start this study from 1990 onward when you had mechanical and Ross procedures available in your facility? Could you explain why you chose the earlier time period?

Dr Alsoufi. Thank you, Dr Starnes. In a retrospective review of outcomes in 2 diverse groups of patients, it might be difficult to perform a fair comparison. Propensity score analysis remains the best analysis method that we can use in this situation. However, there might have been several covariates that we have not identified or used; those unmeasured covariates could have contributed to disparate outcomes in our patients.

Although the surgical era was different between the 2 groups of patients, as you have mentioned, it was not identified as a significant factor for mortality in our risk analysis. We included patients before 1991 to increase the power of our study by adding more patients and having longer follow-up. Moreover, surgical era was one of the variables that we have used to create our propensity score.

Dr Starnes. Well, I have 2 interrelated questions, and I think it pertains to looking at these 2 time periods. It appears from your article that a lot of mechanical valves were used early on, and then you had a tendency in your facility to use Ross procedures later. Therefore I have 2 questions based on that background.

Rheumatic heart disease comprised the largest cohort of patients in your series and represented a risk factor for reoperation. Patients with rheumatic heart disease who underwent a Ross procedure were at even higher risk for reoperation. Do you currently recommend a mechanical prosthesis in these children, or are you currently doing Ross procedures?

Dr Alsoufi. Initially, after adopting the Ross procedure at our institution in 1991, it was offered to all patients. Later, our group was one of the first to report an increased risk of failure after the Ross procedure in patients with rheumatic valve disease. We have identified several risk factors for increased failure rate. Those included patients who had active rheumatic fever at the time of AVR, patients who had pure aortic insufficiency and a dilated annulus larger than $30 \mathrm{~mm}$, and patients who had an aortic annulus $3 \mathrm{~mm}$ or more 
larger than that of the pulmonary valve. In those patients we do not offer the Ross procedure anymore. In addition, we have adopted some technical modifications, most importantly by trimming the muscle rim underneath the autograft with sutures almost going to the annulus level, because we had identified that this muscle often dilated and contributed to late failure. Because we have changed our selection criteria and adapted those modifications in 1999, we have had 2 failures only in patients with rheumatic disease undergoing the Ross procedure. Although the follow-up is not very long, this is an encouraging finding given that most of the failures in the past were evident within the first 3 years after AVR.

Dr Starnes. For my final question, given the high operative mortality in children receiving mechanical valves less than 5 years of age, almost $50 \%$, do you currently use the Ross procedure exclusively in this age group?

Dr Alsoufi. Yes.

Dr Starnes. Again, I would like to thank you for providing me the manuscript, which is excellently written, and thank the Association for the privilege of the discussion.

Dr David J. Cohen (San Antonio, Tex). I had the privilege of visiting your hospital while deployed during Operation Desert Storm, and it was my impression at that time that many of your patients came from many different countries and also from small villages, where long-term follow-up for anticoagulation and for subacute bacterial endocarditis prophylaxis would be impossible to follow. I am wondering if much of the late attrition rate in your patients receiving mechanical valves is related to this issue and whether this would be the same if these patients had been treated, say, in the United States or in Europe?

Dr Alsoufi. The majority of our patients were from Saudi Arabia, even though they came from all over the country. Although anticoagulation follow-up is not done at our hospital but rather at local centers, all those centers have anticoagulation clinics with well-established anticoagulation protocols. The issue of compliance with anticoagulation in children is definitely a major problem. Compliance might be better in the Western world than in other developing countries because of many social, educational, and logistic factors. However, multiple other published series from Europe and the United States showed similar findings, continuous attrition with mechanical valves and high anticoagulation-related morbidity, indicating that anticoagulation control in children remains a problem, even in the Western world.

Dr Themistokles P. Chamogeorgakis (Athens, Greece). As far as neonates, this is a difficult subgroup to manage. Do you have any information or how many neonatal Ross procedures you did or Ross-Konno combinations?

Dr Alsoufi. Our experience with the Ross procedure in infants is limited to 10 patients only, with $1(10 \%)$ death. Therefore despite our large series, the number of infants and neonates is smaller than that seen in other published reports. For the Ross-Konno procedure, we have a large institutional experience, 39 patients with 2 (6\%) deaths.
Dr James H. Oury (Rapid City, SD). I commend you on an excellent series, and it fills a gap, at least in the Ross registry data that we have, including your data, of what happens to these children long-term. Therefore my question is purely from a hemodynamic status, and it is based on the fact that children, by their nature, exercise, sometimes wildly. To get some handle on this, we took about 15 patients from our series and compared them. These were athletes. We compared the athletes undergoing the Ross procedure with a group of so-called normal triathletes, and I can tell you that at extreme exercise in young adults, the results are superimposable. Therefore my question to you is this: Given this unique series, have you had the opportunity of comparing the patients undergoing the Ross procedure with those receiving mechanical valves in terms of their hemodynamic potential and looking at these 2 series as the kids grew older?

Dr Carlos J. Troconis (Caracas, Venezuela). From experiences in undeveloped countries, where noncompliance on conventional anticoagulation treatment is almost the rule and complications from anticoagulation issues were frequently less likely to be found in these population groups, other published series from Europe or from the United States have advocated, in a prospective, nonrandomized, longitudinal multicenter trial, to test the hypothesis that selected patients after AVR with an already established commercial valve can be maintained safely with low-dose aspirin only or with aspirin/clopidogrel.

Although we know that more patients and longer follow-up are required to draw valid conclusions, I particularly think that this anticoagulation modality, when applied to AVR, could be extended to kids. Do you have any observations about that?

Dr Alsoufi. I will answer the last question first. All our patients were anticoagulated with warfarin, with a recommended international normalized ratio range between 2 and 3 . Sometimes we added aspirin for patients in whom maintaining international normalized ratio within the therapeutic range was difficult, but we did not leave them without anticoagulation. Although there are current trials to maintain adult patients who have received a certain mechanical valve while receiving clopidogrel and aspirin only, this is not yet the standard of care, and that valve was not used in our patients.

To answer the first question, although the majority of our patients were asymptomatic, exercise data were largely unavailable. We are currently collecting serial echocardiograms after AVR in children with the purpose of examining trajectories for left ventricular mass regression, recovery of ventricular dilatation, systolic function, and progression of aortic annulus and root diameters, and we hope to share this information with you in future meetings. We do not have current plans to compare exercise performance between children who have undergone a Ross procedure versus those who have received a mechanical valve. Although this has been previously done in adults, no data exist in children, and that will be an excellent study to perform. 


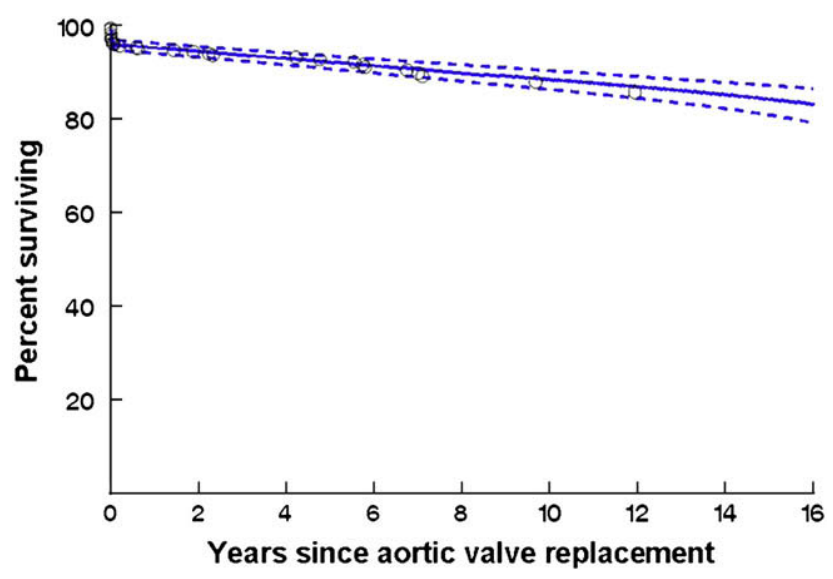

FIGURE E1. Parametric model for overall survival for the entire cohort is composed of 2 phases of risks: an early phase with a high level of risk in the immediate postoperative period and a constant phase indicating a low but increasing risk of attrition over time. The solid lines represent parametric point estimates, and the dashed lines enclose the $95 \%$ confidence interval. Circles represent nonparametric estimates. 


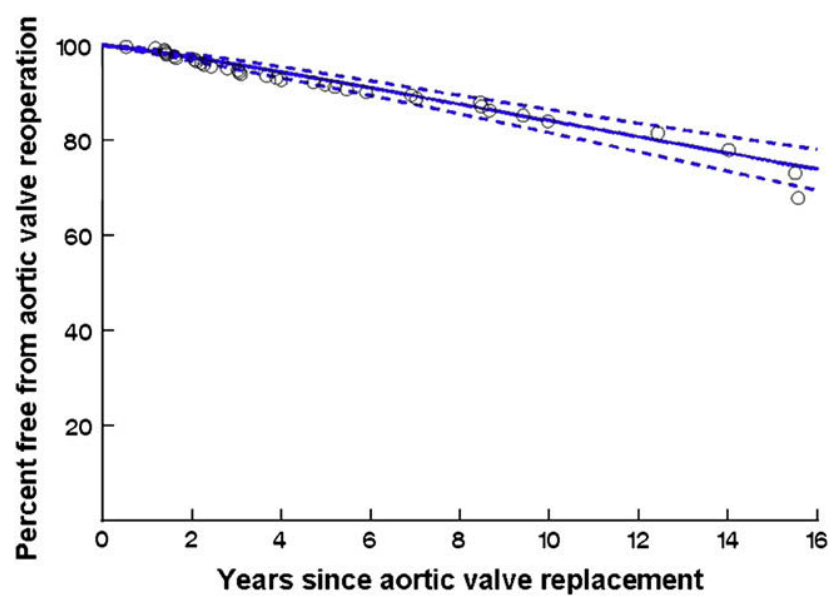

FIGURE E2. Parametric model for survival to aortic valve reoperation for the entire cohort is composed of a late hazard phase that steadily increases as years since surgical intervention progressed. The solid lines represent parametric point estimates, and the dashed lines enclose the $95 \%$ confidence interval. Circles represent nonparametric estimates. 


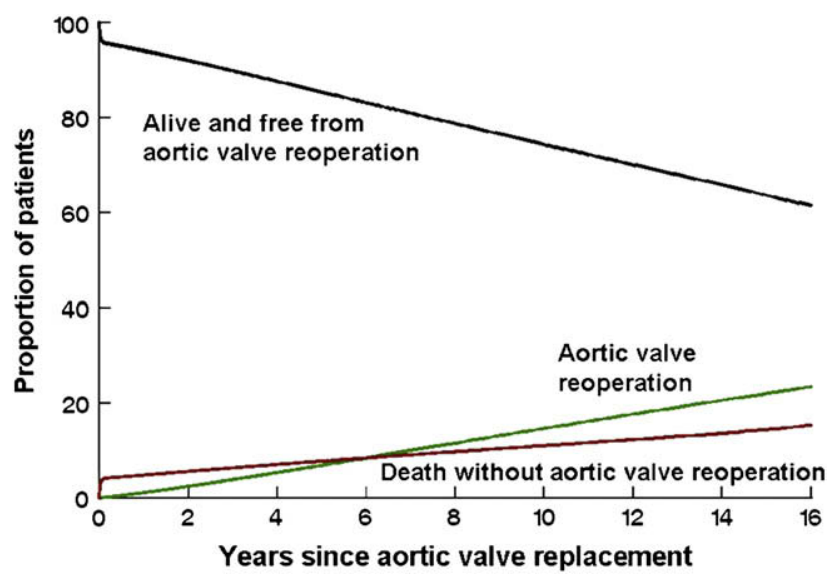

FIGURE E3. Competing risk depiction of outcomes after initial aortic valve replacement. At the time of initial aortic valve replacement, all patients are alive and free from subsequent aortic valve replacement. Aortic valve replacement is associated with an early risk of operative mortality $(4 \%)$, followed by a constant attrition rate. The time-related risk of aortic valve reoperation steadily increases as time from surgical intervention augments. At 10 years after the index procedure, approximately $10 \%$ of patients have died without subsequent aortic valve replacement, $15 \%$ have undergone a second aortic valve replacement, and $75 \%$ are alive and free from subsequent aortic valve replacement. The solid lines represent parametric point estimates. 


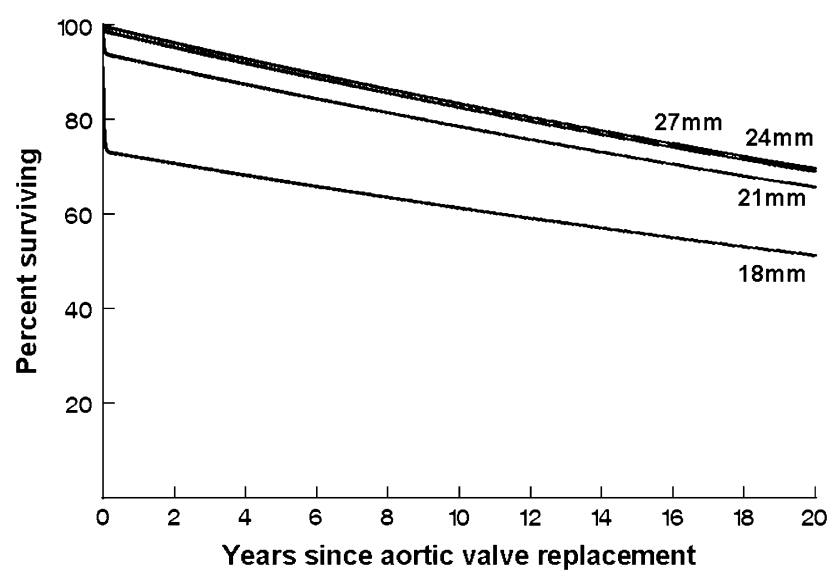

FIGURE E4. Parametric model in patients with mechanical valves for mortality without subsequent aortic valve replacement by initial mechanical valve size. The solid lines represent parametric point estimates. 


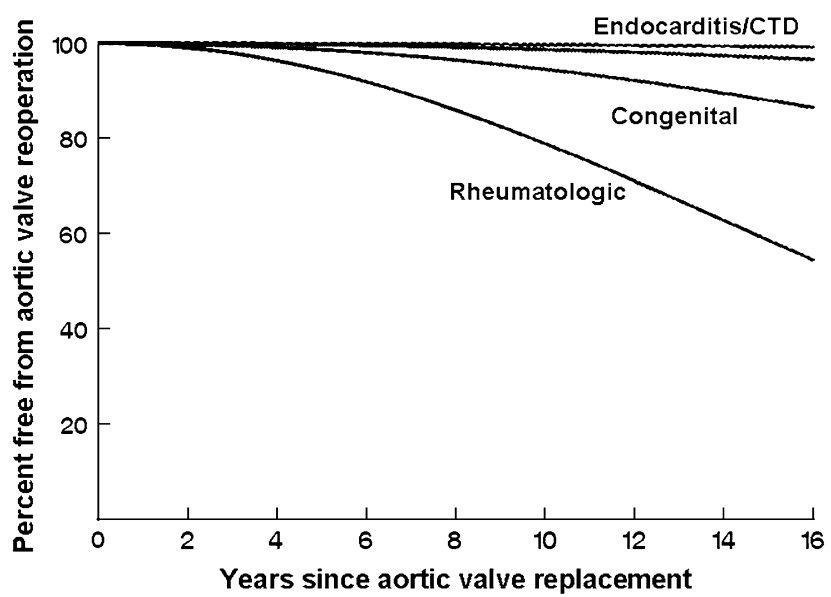

FIGURE E5. Parametric model for survival to subsequent aortic valve reoperation underlying pathology. The solid lines represent parametric point estimates. $C T D$, connective tissue disease. 


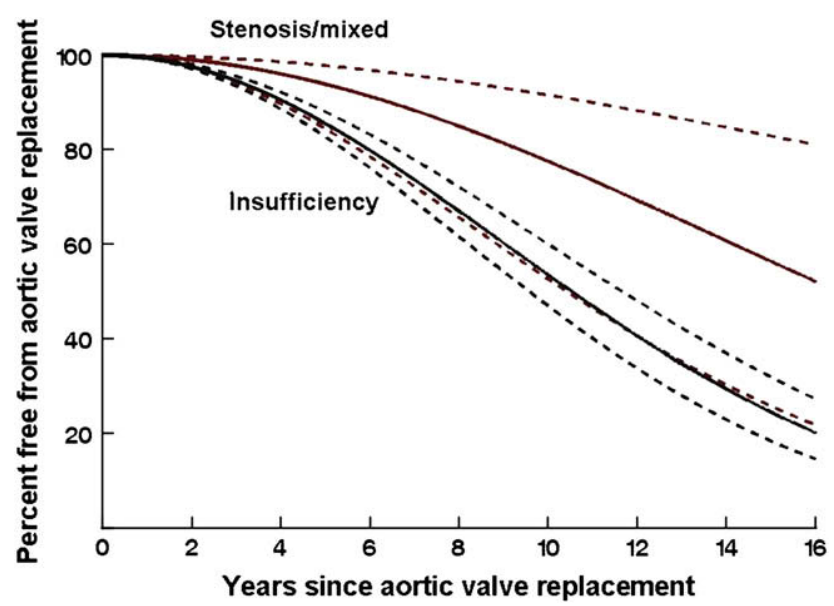

FIGURE E6. Parametric model in patients with a rheumatologic cause who underwent the Ross procedure for survival to subsequent aortic valve reoperation. The solid lines represent parametric point estimates, and the dashed lines enclose the $95 \%$ confidence interval. 


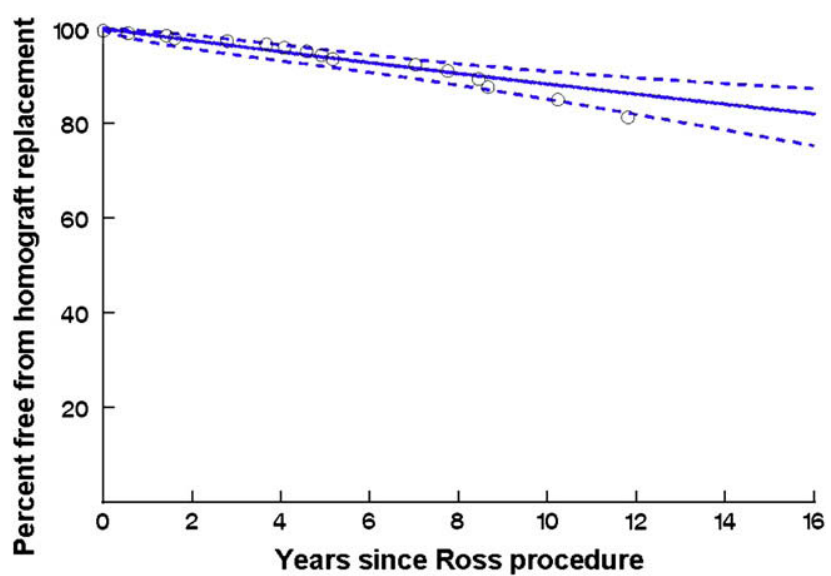

FIGURE E7. Propensity -adjusted effect of initial aortic valve replacement type (Ross procedure or mechanical prosthesis) on survival to any cardiac reoperation. The solid lines represent parametric point estimates, and the dashed lines enclose the $95 \%$ confidence interval. 


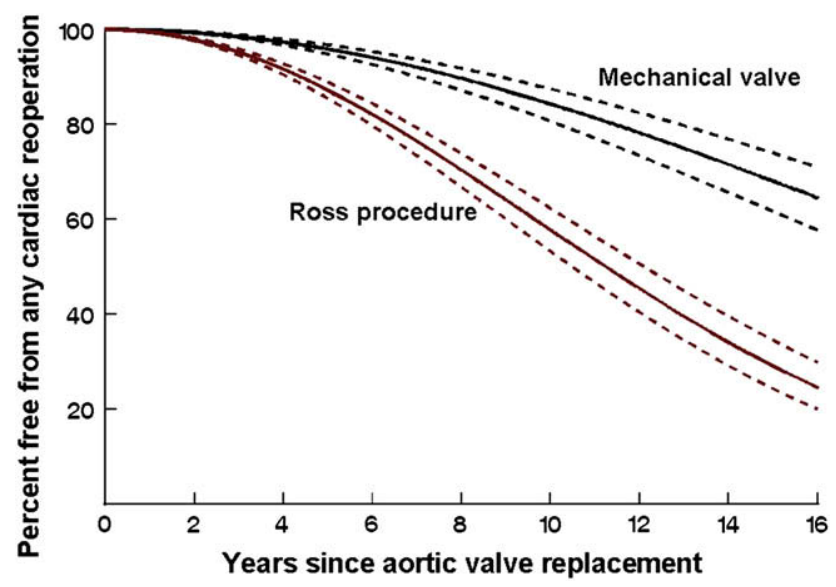

FIGURE E8. Parametric model for survival to homograft replacement for patients who underwent the Ross procedure. The solid lines represent parametric point estimates, and the dashed lines enclose the $95 \%$ confidence interval. Circles represent nonparametric estimates. 
TABLE E1. Factors included in the propensity score

\begin{tabular}{lcc}
\hline & Estimate $\pm \mathbf{S E}$ & $\boldsymbol{P}$ value \\
\hline Year & $-0.112 \pm 0.035$ & .003 \\
Sex (male) & $0.300 \pm 0.190$ & .12 \\
Age at surgical intervention & $0.128 \pm 0.045$ & .005 \\
Rheumatic & $-1.713 \pm 0.540$ & .003 \\
Congenital & $-2.153 \pm 0.644$ & .001 \\
Regurgitation & $1.229 \pm 0.445$ & .006 \\
Additional procedure & $2.086 \pm 0.311$ & $<.0001$ \\
Previous operations & $1.430 \pm 0.365$ & $<.0001$ \\
\hline$S E$, Standard error. & &
\end{tabular}

